\title{
Analysis of Double Heterozygous Haemoglobinopathies from a Tertiary Care Center in North India
}

\author{
Kaniyappan Nambiyar, ${ }^{1}$ Vijay Kumar²*, Sadhna Marwah $^{2}$, Abhay Shanker Nigam ${ }^{2}$ \\ 'Department of Histopathology, Post Graduate Institute of Medical Education and Research, Chandigarh, India \\ ${ }^{2}$ Department of Pathology, Post Graduate Institute of Medical Education and Research \& Dr RML Hospital, New Delhi, India
}

\begin{abstract}
Background: Haemoglobinopathies and thalassemias are inherited conditions, being diagnosed with increasing prevalence in India. The double heterozygosity for $\alpha$ and $\beta$ chain variants leads to the formation of abnormal heterodimer hybrids, which can lead to diagnostic dilemmas. Hematological parameters of double heterozygous conditions have not been analysed much in the literature.

Methods: This study is a retrospective analysis of haemoglobin High Performance Liquid Chromatography (HPLC) from January 2006 to August 2014. Hematological parameters of these patients were also analysed and correlated with respective haemoglobin HPLC findings. Family screening of cases was also done wherever possible.

Result: Out of 6180 cases, 14 cases were found to be of double heterozygous with 10 cases of $\mathrm{Hb}$ E- $\beta$ thalassemias, and 4 cases of $\mathrm{Hb}$ S- $\beta$ thalassemias. In $\mathrm{Hb}$ E- $\beta$ thalassemias, significant negative correlation was noted between haemoglobin and Red cell Distribution Width (RDW) and also between RDW and Red Blood Cell (RBC) count. In Hb S- $\beta$ thalassemias, significant negative correlation was seen between $\mathrm{Hb}$ A2 level and $\mathrm{RBC}$ count.

Conclusion: Although, haemoglobin chain disorders require combination of techniques, HPLC is a cost effective and powerful tool for characterization of these disorders. This study also highlights the importance of hematological parameters ( $\mathrm{Hb}, \mathrm{RDW}$ and $\mathrm{RBC}$ count) in elucidation of double heterozygous haemoglobinopathies from much commoner variants of haemoglobinopathies, particularly in under resourced areas. No similar studies correlating HPLC findings and RBC indices have been found in the literature.
\end{abstract}

Keywords: HPLC, Double Heterozygous Haemoglobinopathies, $\mathrm{Hb}$ E- $\beta$ Thalassemia, Hb S- $\beta$ Thalassemia

\section{Introducation}

Haemoglobinopathies and thalassemias are inherited conditions of abnormal haemoglobin synthesis being diagnosed with increasing prevalence in India. They occur due to changes in the amino acid sequence of either globin chain or decrease in globin chain production. ${ }^{[1]}$ Common haemoglobinopathies in India are thalassemia along with $\mathrm{Hb}$ $\mathrm{S}, \mathrm{Hb} \mathrm{E}, \mathrm{Hb} \mathrm{D}$, and their combinations. ${ }^{[2]}$ Cation exchange high performance liquid chromatography (CE-HPLC) is an excellent tool for accurate and reliable diagnosis of various haemoglobin $(\mathrm{Hb})$ disorders. Haemoglobinopathies can occur either in heterozygous or homozygous states. The double heterozygosity for $\alpha$ and $\beta$ chain variants leads to the formation of abnormal heterodimer hybrids. ${ }^{[1]}$ This results in variable clinical and laboratory features leading to diagnostic dilemmas and delay in diagnosis. So, this study aimed to analyse the haematological and HPLC parameters in cases of double heterozygous haemoglobinopathy, and also to identify correlation between these parameters.

\section{Materials and Methods}

This study was a retrospective analysis of haemoglobin HPLC taken from the medical records of a tertiary care hospital in North India from January 2006 to August 2014. A total of 6180 cases were included in the study. Complete haemogram with $\mathrm{RBC}$ indices was performed on automated cell counter for all the cases. HPLC was performed using VARIANT $^{\mathrm{TM}} \beta$-thalassemia short program and was used for identification of haemoglobinopathies in this study. Family screening of cases was also done wherever possible. Statistical analysis was performed using SPSS version 17 software. Pearson correlation was also done and a $\mathrm{p}$ value less than 0.05 was considered significant.

\section{Results}

Among 6180 patients only 249 (i.e. $4.02 \%$ ) were found to have abnormal haemoglobin fractions. Among the patients having abnormal haemoglobin fractions on HPLC, $14(0.22 \%)$ were found to have double heterozygous haemoglobinopathies.

Hb E- $\boldsymbol{\beta}$ Thalassemia: Patient showing a peak at the $\mathrm{HbA} 2 / \mathrm{E}$ position with increased $\mathrm{HbA} 2$ level $(>15 \%)$ and increased $\mathrm{Hb} F$ level $(5-87 \%)$ was labelled as a double heterozygous state of $\mathrm{Hb} \mathrm{E}$ and $\beta$-thalassemia. ${ }^{[3]} \mathrm{In}$ the present study, $10(0.16 \%)$ patients were diagnosed as $\mathrm{Hb}$ 
$\mathrm{E}-\beta$ thalassemias. The mean value of $\mathrm{Hb} \mathrm{A} 2$ and $\mathrm{Hb} \mathrm{F}$ were $55.8 \pm 15.6 \%$ and $27.2 \pm 17.4 \%$ respectively. Complete haemogram revealed microcytic hypochromic anaemia in all the patients with the mean haemoglobin of $7.3 \mathrm{~g} / \mathrm{dl}$, ranging from 3.1 to $9.5 \mathrm{~g} / \mathrm{dl}$. Mean values of $\mathrm{RBC}$ count, hematocrit, Mean Corpuscular Volume (MCV), Mean Corpuscular haemoglobin (MCH), and Mean corpuscular Haemoglobin Concentration (MCHC) were 3.82 X10 $12 / 1$, $22.8 \%, 60.3 \mathrm{fl}, 19.5 \mathrm{pg}$ and $32.3 \mathrm{~g} / \mathrm{dl}$ respectively. RDW ranged from 21.1 to $40.5 \%$ with a mean of $32.1 \%$ (Table 1 ). Pearson correlation between RBC count and RDW showed a significant negative correlation ( $\mathrm{p}$ value $<0.05$ ). Pearson correlation between $\mathrm{Hb}$ level and RDW also showed a significant negative correlation ( $\mathrm{p}$ value $<0.05$ ).
Hb S- $\boldsymbol{\beta}$ thalassemia: Patient showing a peak at the $\mathrm{S}$-window with increased $\mathrm{Hb}$ A2 (3.5-5.5\%) was labelled as a double heterozygous state of $\mathrm{Hb}-\mathrm{S}$ and $\beta$-thalassemia. ${ }^{[4]}$ In the present study, $4(0.06 \%)$ patients were diagnosed as $\mathrm{Hb} \mathrm{S}-\beta$ thalassemias. The mean value of $\mathrm{Hb} \mathrm{S}$ and $\mathrm{Hb} \mathrm{A} 2$ were found to be $62.8 \pm 14.8 \%$ and $4.7 \pm 0.6 \%$ respectively. The mean value of $\mathrm{Hb} \mathrm{F}$ was found to be $16.3 \pm 5.8 \%$. Complete haemogram revealed microcytic hypochromic anaemia in all the patients except for one case, with the mean haemoglobin of $8.3 \mathrm{~g} / \mathrm{dl}$, ranging from 5.3 to $11 \mathrm{~g} /$ dl. Mean value of HCT, RBC, MCV, MCH, MCHC, and RDW were $25.6 \%, 3.6 \times 10^{12} / 1,69.4 \mathrm{fl}, 23.3 \mathrm{pg}, 33.5 \mathrm{~g} / \mathrm{dl}$ and $25.6 \%$ respectively (Table 1 ). A negative correlation between $\mathrm{Hb} \mathrm{A} 2$ and $\mathrm{RBC}$ count, as well as between $\mathrm{Hb} \mathrm{A} 2$ and HCT ( $\mathrm{p}$ value $<0.05$ ) was noted.

Table 1: HPLC haemoglobin fractions and their haemogram values.

\begin{tabular}{|c|c|c|c|c|c|c|c|c|c|c|}
\hline S.no & $\begin{array}{c}\text { Hb A2 } \\
(\%)\end{array}$ & $\begin{array}{c}\mathrm{Hb} S \\
(\%)\end{array}$ & $\begin{array}{l}\mathrm{Hb} F \\
(\%)\end{array}$ & $\begin{array}{l}\mathrm{Hb} \\
(\mathrm{g} / \mathrm{dl})\end{array}$ & $\begin{array}{c}\text { RBC } \\
(\mathrm{X} 1012 / \mathrm{I})\end{array}$ & $\begin{array}{c}\text { MCV } \\
\text { (fl) }\end{array}$ & $\begin{array}{c}\mathrm{MCH} \\
(\mathrm{pg})\end{array}$ & $\begin{array}{c}\mathrm{MCHC} \\
(\mathrm{g} / \mathrm{dl})\end{array}$ & $\begin{array}{l}\text { RDW } \\
(\%)\end{array}$ & $\begin{array}{r}\text { HCT } \\
(\%)\end{array}$ \\
\hline \multicolumn{11}{|c|}{ Hb E- $\beta$ thalassemia } \\
\hline 1 & 81.1 & - & 9.7 & 9.3 & 4.52 & 60.4 & 20.7 & 34.3 & 21.1 & 27.3 \\
\hline 2 & 74.3 & - & 13 & 8.5 & 4.69 & 56.8 & 18.2 & 32 & 28.2 & 26.7 \\
\hline 3 & 69.5 & - & 15.7 & 6.5 & 4.41 & 47.5 & 14.8 & 31.3 & 34 & 20.9 \\
\hline 4 & 59.3 & - & 20.1 & 7.8 & 4.31 & 60.4 & 18.2 & 30.2 & 31.4 & 26 \\
\hline 5 & 53.5 & - & 37.2 & 3.1 & 1.71 & 64.3 & 21.2 & 33 & 39.3 & 11 \\
\hline 6 & 52.7 & - & 17.3 & 6.3 & 2.86 & 68.6 & 22 & 32 & 40.5 & 19.6 \\
\hline 7 & 49.3 & - & 45.2 & 9.5 & 4.68 & 63.1 & 20.4 & 32.4 & 24.5 & 29.5 \\
\hline 8 & 48.2 & - & 44.3 & 7.3 & 3.85 & 58.9 & 19.1 & 32.4 & 35.5 & 22.5 \\
\hline 9 & 40.5 & - & 58.5 & 6.8 & 3.55 & 58.9 & 19.2 & 32.6 & 30.9 & 20.9 \\
\hline 10 & 30 & - & 11.3 & 8 & 3.68 & 65 & 21.7 & 33.4 & 35.8 & 23.9 \\
\hline \multicolumn{11}{|c|}{ Hb S- $\beta$ thalassemia } \\
\hline 11 & 5.4 & 77 & 11 & 5.3 & 2.19 & 68.6 & 26.7 & 38.9 & 22.9 & 15 \\
\hline 12 & 5.1 & 69.6 & 19.1 & 6 & 3.04 & 64.4 & 19.9 & 30.8 & 34 & 19.6 \\
\hline 13 & 4.3 & 62.2 & 23.2 & 11 & 4.90 & 72 & 22.5 & 31.2 & 22.7 & 35.3 \\
\hline 14 & 4.1 & 42.4 & 11.9 & 10.9 & 4.53 & 72.6 & 24.2 & 33.3 & 23 & 32.8 \\
\hline
\end{tabular}

Table 2: Comparison of prevalence with other studies.

\begin{tabular}{|l|c|c|}
\hline Diagnosis & Study & Prevalence (\%) \\
\hline \multirow{3}{*}{ Hb E- $\beta$ thalassemia } & Present & 0.16 \\
\cline { 2 - 3 } & Mohanty D et al [7] & 0.19 \\
\cline { 2 - 3 } & Baruah MK et al [8] & 2.14 \\
\hline \multirow{3}{*}{ Hb S- $\beta$ thalassemia } & Present & 0.06 \\
\cline { 2 - 3 } & Mohanty D et al [7] & 0.02 \\
\cline { 2 - 3 } & Baruah MK et al [8] & 0.6 \\
\hline
\end{tabular}


Table 3: Comparison of HPLC haemoglobin fraction with other study.

\begin{tabular}{|c|c|c|c|c|}
\hline Diagnosis & Study & Hb A2 (\%) & $\mathrm{Hb} F(\%)$ & Hb S (\%) \\
\hline \multirow{2}{*}{$\mathrm{Hb}$ E- $\beta$ thalassemia } & Present & $55.8 \pm 15.6$ & $27.2 \pm 17.4$ & - \\
\hline & Baruah MK et al [8] & $56.7 \pm 9.6$ & $30.7 \pm 10.1$ & - \\
\hline \multirow{2}{*}{$\mathrm{Hb} \mathrm{S}-\beta$ thalassemias } & Present & $4.7 \pm 0.6$ & $16.3 \pm 5.8$ & $62.8 \pm 14.8$ \\
\hline & Baruah MK et al [8] & $6.3 \pm 0.9$ & $18.9 \pm 8.7$ & $69.3 \pm 9.2$ \\
\hline
\end{tabular}

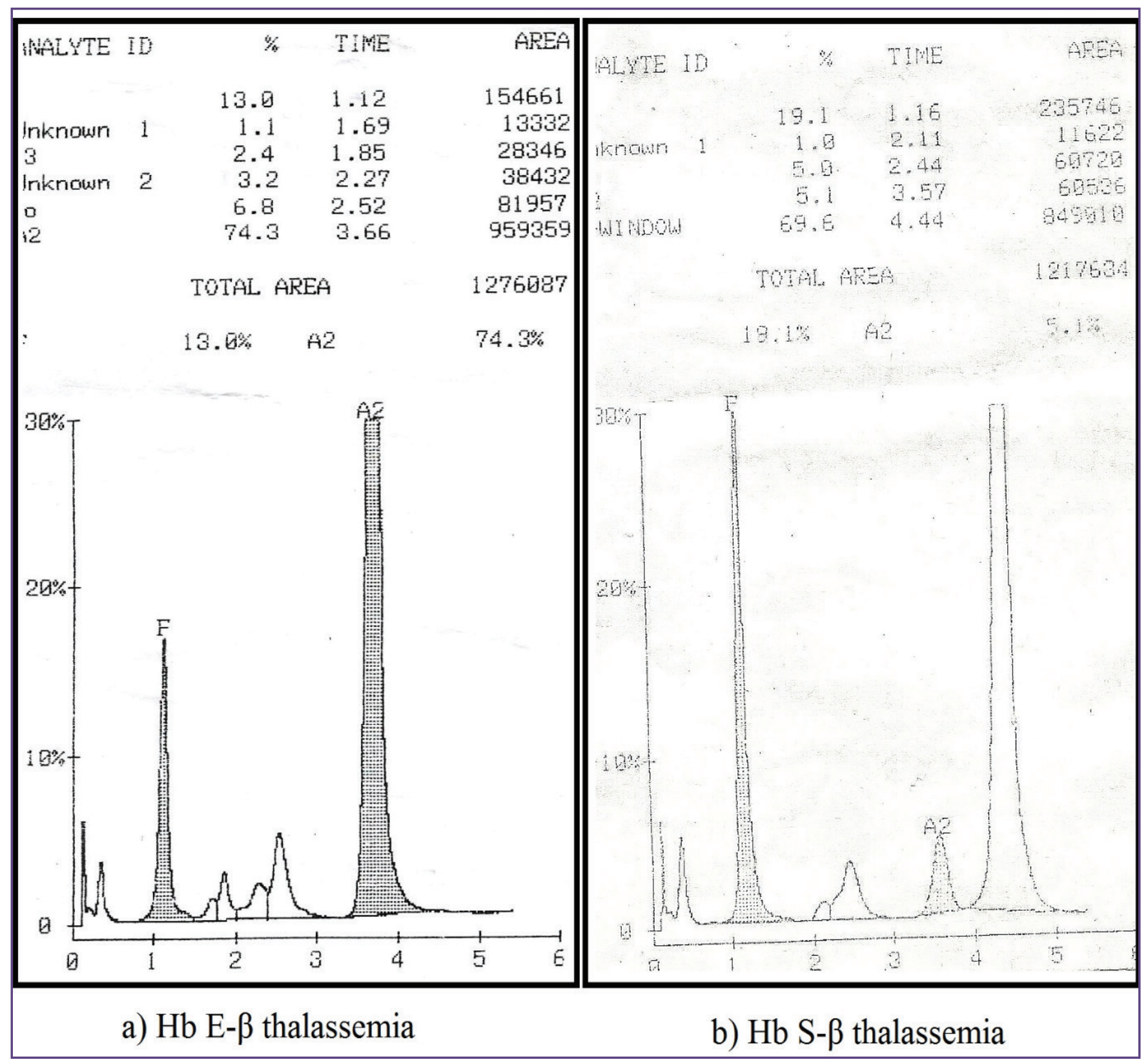

Fig. 1: a) Double heterozygous state of $\mathrm{Hb} \mathrm{E}$ and $\beta$-thalassemia b) Double heterozygous state of Hb-S and $\beta$-thalassemia. 


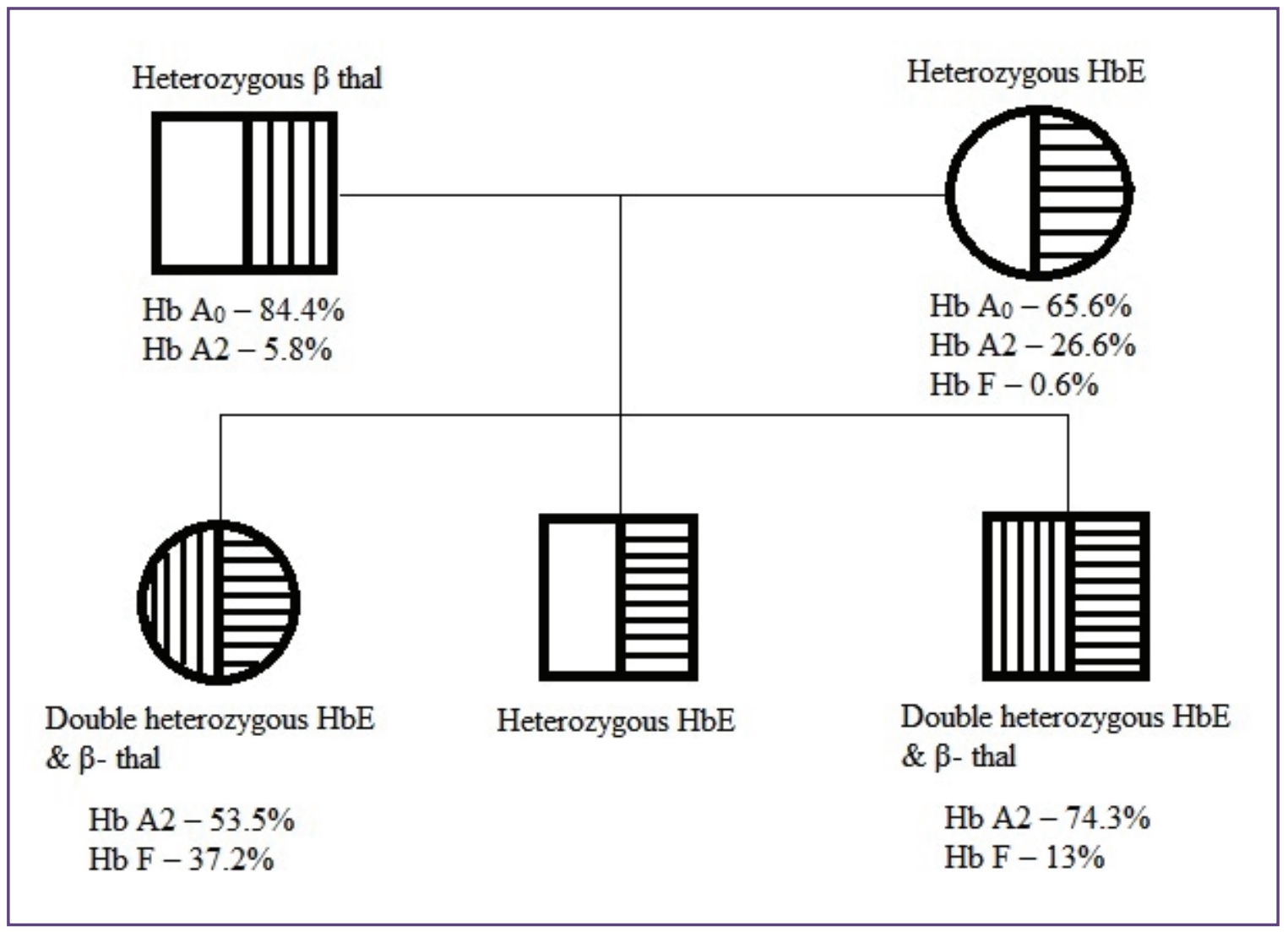

Fig. 2: Family study of double heterozygous $\mathrm{Hb} \mathrm{E}$ and $\beta$-thalassemia.

\section{Discussion}

The coinheritance of two different haemoglobinopathies is a rare occurrence. Although, they superficially resemble the non-coinherited variants, they show subtle variations in clinical, laboratory and management aspects. Among the laboratory investigations, HPLC is useful in presumptive diagnosis of various haemoglobinopathies. Although, DNA based techniques are needed for better delineation of these disorders, HPLC analysis in conjunction with clinical profile and different haematological parameters is pertinent for evaluation of double heterozygous haemoglobinopathies.

The cumulative frequency of haemoglobinopathies in India has been found to be $4.2 \%$ in a previous study. ${ }^{[5]} \mathrm{A}$ comparable frequency of haemoglobin chain disorders $(4.02 \%)$ was observed in our study.

Hb E- $\boldsymbol{\beta}$ Thalassemia: Patients having double heterozygous state of $\mathrm{Hb} \mathrm{E}$ and $\beta$-thalassemia is characterized by marked clinical variability ranging from mild and asymptomatic anaemia to a life-threatening disorder requiring transfusions from infancy. ${ }^{[6]}$ This is different from other double heterozygous states for structural $\beta$-chain variants and $\beta$-thalassemia. A study by Mohanty $\mathrm{D}$ et al ${ }^{[7]}$ reported a prevalence of $0.19 \%$ which is similar to the present study $(0.16 \%)$. Higher prevalence $(2.14 \%)$ noted in the study by Baruah MK et al ${ }^{[8]}$ is due to regional variation of haemoglobin disorders in India (Table 2). Mean values of $\mathrm{HbA} 2$ and $\mathrm{Hb} \mathrm{F}$ in this study were similar to another study by Baruah MK et al ${ }^{[8]}$ (Table 3 ). In addition, there was a negative correlation between RDW and $\mathrm{Hb}$ and also between RDW and RBC count ( $p$ value $<0.05$ ). However, no studies correlating HPLC findings and RBC indices have been found in the literature. Family study of two cases in the same family has been depicted in figure 2 . Similar family study for diagnosis of double heterozygous conditions has also been used in other studies. ${ }^{[1,9]}$

Hb S- $\boldsymbol{\beta}$ Thalassemia : Hb S- $\beta$ thalassemia is a double heterozygous state of $\mathrm{Hb} \mathrm{S}$ and $\beta$-thalassemia. The clinical course is similar to that of $\mathrm{Hb} \mathrm{SS}$, however anaemia is comparatively milder than in sickle cell anaemia ${ }^{[4]}$. A study by Mohanty D et al ${ }^{[7]}$ reported a prevalence of $0.02 \%$ which compares favourable with our study $(0.06 \%)$. Higher prevalence $(0.6 \%)$ noted in the study by Baruah MK et al ${ }^{[8]}$ is due to regional variation of haemoglobin 
disorders in India (Table 2). Previous study showed mean values of $\mathrm{MCV}$ for $\mathrm{Hb} \mathrm{S}-\beta^{+}$thalassemias and $\mathrm{Hb} \mathrm{S}-\beta^{0}$ thalassemias to be $72 \mathrm{fl}$ and $67.8 \mathrm{fl}$ respectively ${ }^{[4]}$ and a comparable mean value of MCV of $69.4 \mathrm{fl}$ was noted in our study. Mean values of $\mathrm{Hb} \mathrm{S}, \mathrm{HbA} 2$ and $\mathrm{Hb} \mathrm{F}$ in this study were similar to another study by Baruah MK et al ${ }^{[8]}$ (Table 3). There was a negative correlation between $\mathrm{Hb} \mathrm{A} 2$ and RBC count as well as between Hb A2 and HCT ( $\mathrm{p}$ value < 0.05 ). No similar studies correlating these parameters have been found in the literature.

\section{Conclusion}

In conclusion, rarity of these disorders makes the diagnosis challenging. Haemoglobin chain disorders require a combination of techniques including HPLC, which is one of the most important diagnostic modality for elucidation of double heterozygous cases. Diagnostic difficulties are encountered by overlapping laboratory findings, prompting the search for newer parameters. Hematological parameters like haemoglobin level, RBC indices, and $\mathrm{Hb}$ A2 level and their correlation are important for characterization of double heterozygous state. This study highlights the significant negative correlation between RDW and $\mathrm{Hb}$ as well as RDW and RBC count in double heterozygous cases of $\mathrm{Hb}$ E- $\beta$ thalassemia ( $p$ value $<0.05$ ), which helps particularly in elucidation of challenging cases. Role of family screening in a suspected case is also crucial. To the best of our knowledge, correlation of different hematological parameters for characterization of double heterozygous haemoglobinopathies has not been reported so far in the Indian literature. However, further studies including larger number of cases are required to validate the statistical correlation. This may unmask significant haematological parameters, which lead to better diagnostic evaluation and understanding of these disorders particularly in under resourced areas.

\section{Reference}

1. Mutreja D, Tyagi S, Tejwani N, Dass J. Double heterozygous hemoglobin Q India/hemoglobin D Punjab hemoglobinopathy: Report of two rare cases. Indian J Hum Genet. 2013;19(4):479-82.

2. Agarwal MB. The burden of haemoglobinopathies in India--time to wake up? The Journal of the Association of Physicians of India. 2005;53:1017-8.

3. Bain BJ. Other significant hemoglobinopathies. In: Bain BJ editor. Haemoglobinopathy diagnosis. 2nd edn. Massachusetts: Blackwell Publishing Ltd; 2006. 206-9.

4. Bain BJ. Sickle cell hemoglobin and its interactions with other variant haemoglobins and with thalassaemias. In: Bain BJ editor. Haemoglobinopathy diagnosis. 2nd edn. Massachusetts: Blackwell Publishing Ltd; 2006. 170-3.

5. Sarnaik SA. Thalassaemia and related haemoglobinopathies. Indian J Pediatr. 2005;72:319-24.

6. Olivieri NF, Pakbaz Z, Vichinsky E. Hb E/beta-thalassaemia: a common \& clinically diverse disorder. Indian J Med Res. 2011;134:522-31.

7. Mohanty D, Colah RB, Gorakshakar AC, Patel RZ, Master DC, Mahanta J, et al. Prevalence of beta-thalassemia and other haemoglobinopathies in six cities in India: a multicentre study. J Community Genet. 2013;4(1):33-42.

8. Baruah MK, Saikia M, Baruah A. Pattern of hemoglobinopathies and thalassemias in upper Assam region of North Eastern India: high performance liquid chromatography studies in 9000 patients. Indian J Pathol Microbiol. 2014;57(2):236-43.

9. Rao S, Kar R, Gupta SK, Chopra A, Saxena R. Spectrum of haemoglobinopathies diagnosed by cation exchange-HPLC \& modulating effects of nutritional deficiency anaemias from north India. Indian J Med Res. 2010;132:513-9.

*Corresponding author:

Dr.Vijay Kumar, Room no: 315, Third floor, OPD building, Department of Pathology, Post Graduate Institute of Medical Education and Research \& Dr RML Hospital, New Delhi, India- 110001

Phone: +91 9560204567

Email: vijaypgi1@gmail.com

Date of Submission : 12.02.2017

Financial or other Competing Interests: None. 